\title{
Fiziksel Tıp ve Rehabilitasyon Polikliniğine Başvuran 18 Yaş Altı Hastaların Değerlendirilmesi
}

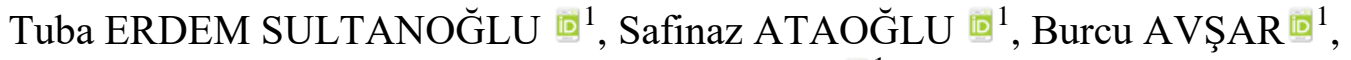 \\ Mehmet Naci ÇAKIR ${ }^{1}$
}

ÖZ

Amaç: Çalışmamızın amacı fiziksel tıp ve rehabilitasyon polikliniğine kas-iskelet sistemi ağrısı ve sağlık kurulu için başvuran 18 yaş ve altı hastaların demografik ve klinik özelliklerinin değerlendirilmesidir.

Gereç ve Yöntemler: Çalışmamızda Haziran 2019-Haziran 2020 tarihleri arasında kas iskelet sisteminde ağrı şikayeti ve engelli sağlık kurulu için başvuran 18 yaş ve altı hastalara ait veriler kesitsel ve retrospektif araştırma modeli şeklinde incelendi. Hastaların demografik ve klinik özellikleri kaydedildi. Kas-iskelet sistemi ağrısıyla başvuran hastaların ağrı etiyolojisi ve bölgesi, ağrı süresi, ailede romatolojik hastalık öyküsü ve uygulanan tedavileri kaydedildi.

Bulgular: Çalışmaya 1000 hasta dahil edildi. Hastaların \%23,4’ü kas iskelet sisteminde ağrı şikayetiyle, \%67,8‘i engelli sağllk kuruluna başvurmak amacıyla ve $\% 8,8$ 'i ise fizyoterapi için gerekli olan sağlık raporuna başvurmuştu.

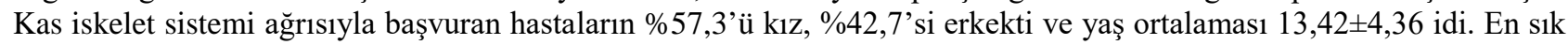
ağrı etiyolojisi enflamatuvar artritlerdi $(\% 42,3)$. En fazla başvuru şikayeti el bilek ve el eklemlerinde ağrı $(\% 23,9)$ ve bel-sırt ağrısı $(\% 22,6)$ idi. Hastaların \%51,3'ünde akut, \%48,7'sinde kronik ağrı vardı. Ailede romatizmal hastalık öyküsü hastaların $\% 8,1$ 'inde mevcuttu. $\% 50,9$ medikal tedavi, $\% 31,2$ ev egzersiz programı, $\% 9,4$ medikal tedavi ve ev egzersiz program1, \%7,3 fizyoterapi ve \%1,3 konservatif tedavi uyguland1.

Sonuç: Çalışmamızda çocukluk çağı kas iskelet sistemi ağrı şikayetinin en sık nedeni enflamatuvar artritler olarak tespit edildi. Çocuk hastaların daha çok fizyoterapi alabilmek, sosyal ve eğitsel haklardan yararlanmak amacıyla polikliniğe başvurduğu saptandı. Bu nedenle ülkemizde çocuklarda kas-iskelet sistemi ağrısı ve engellilik ile ilgili çok merkezli çalışmaların yapılmasına ihtiyaç vardır.

Anahtar Kelimeler: Çocuk; kas-iskelet ağrısı; engelli çocuklar.

\section{Evaluation of Patients Under the Age of 18 Admitted to the Physical Medicine and Rehabilitation Outpatient Clinic}

\begin{abstract}
Aim: The aim of our study is to evaluate the demographic and clinical characteristics the patients under the age of 18 admitted to the physical and rehabilitation outpatient clinic.

Material and Methods: The data of patients aged 18 and under who applied for musculoskeletal system pain and for the disability health board were analyzed retrospectively. Demographic and clinical characteristics of the patients were recorded. Pain etiology and region, pain duration, family history of rheumatologic disease and treatments were recorded for the musculoskeletal system pain.

Results: 1000 patients were included in the study. $23.4 \%$ of the patients complained of pain in the musculoskeletal system, $67.8 \%$ applied to the health board and $8.8 \%$ applied to the medical report required for the physiotherapy. $57.3 \%$ of the patients who applied with musculoskeletal pain were female and $42.7 \%$ were male and the average age was 13.42 \pm 4.36. The most common pain etiology was inflammatory arthritis. The most common complaints were the wristhand joints pain and low back pain. The musculoskeletal pain was acute in $51.3 \%$ and cronic in the $48.7 \%$ of the patients. The family history of the rheumatic disease was in $8.1 \%$. $50.9 \%$ medical treatment, $31.2 \%$ home exercise program, $9.4 \%$ medical treatment and home exercise program, $7.3 \%$ physiotherapy and $1.3 \%$ conservative treatment
\end{abstract}

1 Düzce Üniversitesi, Tıp Fakültesi, Fiziksel Tıp ve Rehabilitasyon Anabilim Dalı, Düzce, Türkiye

Sorumlu Yazar / Corresponding Author: Tuba ERDEM SULTANOĞLU, e-mail: drtubaerdem@gmail.com Geliş Tarihi / Received: 20.07.2020, Kabul Tarihi / Accepted: 17.11.2020 
were applied.

Conclusion: The most common cause of childhood musculoskeletal pain complaint was inflammatory arthritis. It was found that pediatric patients applied to the outpatient clinic in order to get more physiotherapy and benefit from social and educational rights. Therefore, in our country multicenter studies on musculoskeletal pain and disability are needed.

Keywords: Child; musculoskeletal pain; handicapped children.

\section{GÍRIŞ}

Kas-iskelet sistemi ağrısı nedeniyle sağlık kuruluşlarına başvuru okul çağındaki çocuklarda ve gençlerde giderek artan sıklıkta görülmektedir. Çalışmalar okul çağındaki çocukların en az \%15'inin ve ergenlerin \%30'unun kasiskelet ağrısı yaşadığını ve sağlık kuruluşuna başvurduğunu göstermektedir $(1,2)$. Kas-iskelet sistemine bağlı ağrı nedenleri ve sıklığı çocuklarda yaş gruplarına göre farklılıklar gösterir. Ağrının travma, büyüme ağrısı, spesifik olmayan ağrı, romatolojik hastalıklar ve enfeksiyöz nedenler gibi farklı sebepleri olabilmektedir $(3,4)$. Ağrı nedeninin akut döneminde tespiti ve tedavisi önemlidir. Çocukluk çağında ağrının kronik hale gelmesi çocuğun fiziksel, sosyal, psikolojik ve akademik gelişimini olumsuz etkileyebilir. Ayrıca kronik kas iskelet sistemi ağrısıyla tekrarlayan hastane başvuruları aileyi olumsuz etkileyebilir; sağlık harcamalarının artmasına neden olabilir $(5,6)$. Bu nedenle kas-iskelet sistemi ağrı sebeplerinin ve sıklıklarının bulunması sağlık hizmetlerinin planlanmasında önem taşır.

Özürlülük bireyleri, aileleri ve toplumu yakından etkileyen bir durumdur. Fiziksel Tip ve Rehabilitasyon (FTR) polikliniğine fizyoterapi alabilmek, sosyal ve eğitsel haklardan yararlanmak amacıyla çocuk ve ergen hastalar yönlendirilmekte veya başvuruda bulunmaktadır. Başvuran hastaların özür ve sağlık durumunun, özürlülük oranlarının, yararlanabileceği eğitim ve sosyal hakları belirten raporların düzenlenmesi için hastanelerde bulunan engelli sağlık kurullarına yönlendirilmektedir. $\mathrm{Bu}$ yönlendirme öncesinde çocuğun ayrıntılı fiziyatrik değerlendirmesinin yapılması, tanının belirlenmesi, kas iskelet sistemi kayılarının koruyucu ve tedavi edici hizmetlerle en alt düzeye indirilmesi, rehabilitasyon planlaması ile yaşama katılımlarının sağlanması, rapor sürecinin aileye anlatılması önem taşır; süreçlerinin tümünde fiziyatriste önemli görevler düşmektedir (7-9).

Çalışmamızda FTR polikliniğine kas-iskelet sistemi ağrısı ve sağlık kurulu için başvuran 18 yaş ve altı hastaların demografik ve klinik özelliklerinin değerlendirilmesi amaçlanmıştır.

\section{GEREÇ VE YÖNTEMLER}

Çalışmamızda Düzce Üniversitesi Araştırma ve Uygulama Hastanesi FTR polikliniğine Haziran 2019Haziran 2020 tarihleri arasında kas iskelet sistemi ağrısı ve engelli sağlık kurulu için başvuran 18 yaş ve altı hastalara ait veriler kesitsel ve retrospektif araştırma modeli şeklinde incelendi. Düzce Üniversitesi Etik Kurul onayı oturum ve sayı 2020/95 olacak şekilde, 01.06.2020 tarihinde alındı. Tüm prosedürler kurumsal ve/veya ulusal araştırma komitesinin etik standartlarına ve 2004 Helsinki Bildirgesi'ne uygun olarak yürütüldü.
Hastalara ait bilgilere hastane otomasyon sistemi ve hasta dosyalarından ulaşıldı. Psikiyatrik, nefrolojik, kardiyovasküler, pulmoner hastalığı, malignensisi olanlar ve 18 yaşın üstündeki hastalar çalışmaya dahil edilmedi. Tekrarlayan başvurusu olan hastalar için ilk başvurudaki bilgiler alınd.

Hastaların yaşı ve cinsiyeti, polikliniğe başvuru nedeni (kas iskelet sisteminde ağrı, engelli sağlık kurulu, fizik tedavi ve rehabilitasyon uygulamaları için gerekli olan sağlık raporu), kas-iskelet sistemi ağrı etiyolojisi ve bölgesi, ağrı süresi, ailede romatolojik hastalık öyküsü, uygulanan tedaviler kaydedildi.

Kas iskelet sistemi ağrı etiyolojisi ve başvuru esnasındaki ağrı konu ile ilgili daha önce yapılmış çalışmalar referans alınarak yapıldı. Ağrı etiyolojisi spesifik olmayan ağrı (travma ile ilişkili olmayan, kendi kendini sınırlayan ve kas iskelet sistemi muayenesi normal olan), enflamatuvar artritler (juvenil idiyopatik artrit, reaktif artrit), skolyoz (omurganın koronal planda laterale deviasyonu, sagittal planda hipokifoz, lordoz, aksiyal planda ise rotasyonu ile karakterize postural bir bozukluğu; radyolojik olarak ise Cobb açısının 10 derece ve üstünde olduğu eğriliği), lomber intervertebral disk hastalığı (diskin lomber spinal sinir kökünü sıkıştırması ile ortaya çıkan bel ve bacak ağrısı ile karakterize, nörolojik defisiti olmayan, konservatif tedavinin tercih edildiği) travma (kontüzyon, kırık, strain, sprain) ve büyüme ağrısı olarak sınıflandırıldı. Enflamatuvar artritlerde juvenil idiyopatik artrit ve reaktif artrit değerlendirildi. Çocukluk çağında en sık görülen ve enflamatuvar artrit nedeni olan juvenil idiyopatik artrit 16 yaşından önce başlayan, bilinen etyolojik neden olmaksızın ortaya çıkan, sistemik bulgu ve yakınmalarla beraber sabah tutukluğu ve artraljinin yanında 6 haftadan uzun süren artrit kliniğinin olduğu kronik enflamatuvar bir hastalık olarak tanımlanır. Reaktif artritte eklem dışında bir enfeksiyonu özellikle gastrointestinal veya genitoüriner sistem enfeksiyonlarını takiben gelişen artrit tablosu vardır $(3,4)$.

Ağrı bölgesi yumuşak doku (kas, tendon, ligaman), kalça/pelvis, diz, ayak bileği ve ayak eklemleri, el bileği ve el eklemleri, dirsek, omuz, boyun, bel ve sirt olarak sinıflandirıldi (10).

Ağr1 süresi 3 ayın altındakiler akut ağr1, 3 ay ve üzeri olanlar kronik ağrı olarak değerlendirildi (11).

Uygulanan tedavi yöntemleri konservatif tedaviler (istirahat, elevasyon, soğuk veya sicak uygulama), medikal tedavi, medikal tedavi ve ev egzersiz programı, fizik tedavi uygulaması şeklinde gruplandırıldı.

\section{İstatistiksel Analiz}

Verilerin analizi Windows için SPSS (Statistical Package for Social Sciences) 23.0 versiyon paket programı kullanılarak yapıldı ve tanımlayıcı istatistikler (ortalama, standart sapma, yüzde değer) hesapland.

\section{BULGULAR}

Bir y1l içinde FTR polikliniğine başvurusu olan 18 yaş ve altı 1000 hasta çalışmaya dahil edildi. Hastaların \%45,2 $(\mathrm{n}=452) \mathrm{k} 1 \mathrm{z}, \% 54,8 \quad(\mathrm{n}=548)$ erkekti ve yaş ortalaması $10,4 \pm 4,5$ idi. Yaş aralığı olarak \%20,8'i 0-6 yaş ve \%79,2'si 7-18 yaş hasta grubundan oluşmaktayd1. Kas iskelet sisteminde ağrı şikayeti ile başvuran hasta oranı $\% 23,4(\mathrm{n}=234)$ idi. Poliklinik başvurusu olan \% 67,8 $\mathrm{i}$ $(n=678)$ engelli sağlık kurulu için; \% 8,8'i $(n=88)$ ise 
fizik tedavi ve rehabilitasyon uygulamaları için gerekli olan, FTR uzman hekiminin yer aldığı üçüncü basamak sağlık kurumlarınca düzenlenen sağlık raporu için başvuran hasta idi (Tablo 1). Engelli sağlık kuruluna başvuran hastaların \%56,3'ü serebral palsi, \%17'si psikiyatrik nedenle başvuru, \%12,6's1 kas hastalıkları, \%9,4'ü kromozom anomalileri, \%4,7'si konjenital malformasyon tanısı olan hastalard1 (Tablo 2).

Tablo 1. Tüm hastaların demografik verileri

\begin{tabular}{|c|c|c|c|}
\hline & & Ortalama & $\begin{array}{c}\text { Standart } \\
\text { Sapma }( \pm)\end{array}$ \\
\hline \multicolumn{2}{|l|}{ Yaş } & 10,4 & 4,5 \\
\hline & & Sayı (n) & Yüzde (\%) \\
\hline \multirow[t]{2}{*}{ Cinsiyet } & $\mathrm{K}_{1 \mathrm{Z}}$ & 452 & 45,2 \\
\hline & Erkek & 548 & 54,8 \\
\hline \multirow{3}{*}{$\begin{array}{l}\text { Polikliniğe } \\
\text { başvuru } \\
\text { nedeni }\end{array}$} & Ağr1 & 234 & 23,4 \\
\hline & $\begin{array}{l}\text { Sağlık } \\
\text { raporu }\end{array}$ & 88 & 8,8 \\
\hline & $\begin{array}{l}\text { Engelli } \\
\text { raporu }\end{array}$ & 678 & 67,8 \\
\hline
\end{tabular}

Tablo 2. Engelli sağlık kurulu için başvuran hastaların tanı siniflamas1

\begin{tabular}{|l|c|c|}
\hline & Say1 (n) & Yüzde (\%) \\
\hline Serebral palsi & 382 & 56,3 \\
\hline $\begin{array}{l}\text { Psikiyatrik nedenle } \\
\text { başvuru }\end{array}$ & 115 & 17 \\
\hline Kas hastalıkları & 85 & 12,6 \\
\hline Kromozomal anomali & 64 & 9,4 \\
\hline $\begin{array}{l}\text { Konjenital } \\
\text { malformasyon }\end{array}$ & 32 & 4,7 \\
\hline
\end{tabular}

Tablo 3. Ağrı şikayetiyle başvuran hastaların demografik ve klinik özellikleri

\begin{tabular}{|l|l|c|c|}
\hline \multirow{4}{*}{ Cinsiyet } & & Sayı (n) & Yüzde (\%) \\
\cline { 2 - 4 } & K1z & 134 & 57,3 \\
\hline \multirow{4}{*}{$\begin{array}{l}\text { Ağrı } \\
\text { etiyolojisi }\end{array}$} & $\begin{array}{l}\text { Spesifik } \\
\text { olmayan ağrı }\end{array}$ & 55 & 23,5 \\
\cline { 2 - 4 } & $\begin{array}{l}\text { Enflamatuvar } \\
\text { artrit }\end{array}$ & 99 & 42,3 \\
\cline { 2 - 4 } & $\begin{array}{l}\text { Skolyoz } \\
\text { intervertebral } \\
\text { disk hastalığ1 }\end{array}$ & 14 & 11,5 \\
\cline { 2 - 4 } & Travma & 32 & 6,0 \\
\cline { 2 - 4 } & $\begin{array}{l}\text { Büyüme } \\
\text { ağrısı }\end{array}$ & 7 & 3,7 \\
\cline { 2 - 4 } & Var & 19 & 8,1 \\
\hline $\begin{array}{l}\text { Ailede } \\
\text { romatolojik } \\
\text { hastalık } \\
\text { öyküsü }\end{array}$ & Yok & 215 & 91,9 \\
\hline
\end{tabular}

Kas iskelet sistemi ağrısıyla başvuran hastaların \%57,3'ü $(\mathrm{n}=134) \mathrm{k} 1 \mathrm{z}, \% 42,7$ 'si $(\mathrm{n}=100)$ erkekti ve yaş ortalaması $13,42 \pm 4,36$ idi. En sık kas iskelet sistemi ağrı etiyolojisi $\% 42,3$ enflamatuvar artritlerdi; bu hastaların takip ve tedavisi FTR polikliniğinde yapıldı. Hastaların \%23,5'inde ise travma ile ilişkili olmayan, kendi kendini sinırlayan ve kas iskelet sistemi muayenesi normal olan spesifik olmayan ağrı mevcuttu. Başvuru şikayetleri en çok el bilek ve el eklemlerinde ağrı $(\% 23,9)$ ve bel-sırt ağrıs1 $(\% 22,6)$ şeklindeydi. Hastaların \%51,3'ünde akut, \%48,7'sinde kronik kas-iskelet sistemi ağrısı vardı. Ailede romatizmal hastalık öyküsü hastaların \%8,1'inde tespit edildi. Hastalara uygulanan tedavi yöntemlerini incelediğimiz çalışmamızda hastaların \%50,9'unda medikal tedavi, \%31,2'sinde ev egzersiz program1, $\% 9,4$ 'ünde medikal tedavi ve ev egzersiz programı, $\% 7,3$ 'ünde fizik tedavi uygulamaları ve \%1,3'ünde konservatif yöntemlerle tedavi edildiği saptandı (Tablo 3 ve 4).

Tablo 4. Ağrı şikayetiyle başvuran hastaların demografik ve klinik özellikleri

\begin{tabular}{|l|l|c|c|}
\hline & & Say1 (n) & Yüzde (\%) \\
\hline \multirow{5}{*}{$\begin{array}{l}\text { Ağrı } \\
\text { bölgesi }\end{array}$} & $\begin{array}{l}\text { Yumuşak doku } \\
\text { kaynaklı ağrı }\end{array}$ & 34 & 14,5 \\
\cline { 2 - 4 } & Kalça, pelvis & 23 & 9,8 \\
\cline { 2 - 4 } & Diz & 25 & 10,7 \\
\cline { 2 - 4 } & $\begin{array}{l}\text { Ayak bileği- } \\
\text { ayak eklemleri }\end{array}$ & 18 & 7,7 \\
\cline { 2 - 4 } & $\begin{array}{l}\text { El bileği-el } \\
\text { eklemleri }\end{array}$ & 56 & 23,9 \\
\cline { 2 - 4 } & Dirsek & 4 & 1,7 \\
\cline { 2 - 4 } & Omuz & 7 & 3,0 \\
\cline { 2 - 4 } & Boyun & 14 & 6,0 \\
\cline { 2 - 4 } & Bel-sırt & 53 & 22,6 \\
\hline \multirow{4}{*}{$\begin{array}{l}\text { Ağrı } \\
\text { süresi }\end{array}$} & Akut ağr1 & 120 & 51,3 \\
\cline { 2 - 4 } & Kronik ağr1 & 114 & 48,7 \\
\hline \multirow{4}{*}{$\begin{array}{l}\text { Uygulanan } \\
\text { tedavi }\end{array}$} & $\begin{array}{l}\text { Konservatif } \\
\text { yöntemler }\end{array}$ & 3 & 1,3 \\
\cline { 2 - 4 } & Medikal tedavi & 119 & 50,9 \\
\cline { 2 - 4 } & $\begin{array}{l}\text { Medikal tedavi } \\
\text { ve ev egzersizi }\end{array}$ & 22 & 9,4 \\
\cline { 2 - 4 } & Fizik tedavi & 17 & 7,3 \\
\cline { 2 - 4 } & Ev egzersizi & 73 & 31,2 \\
\hline
\end{tabular}

\section{TARTISSMA VE SONUÇ}

FTR polikliniğine başvurusu olan 18 yaş ve altı hastaları incelediğimiz çalışmamızda hastaların \%23,4'ünün kas iskelet sisteminde ağrı şikayeti nedeni ile başvurduğu bulunmuştur. Kas iskelet sistemi ağrısı dişındaki başvuru nedenlerinin \%67,8'inin engelli raporu ve \% 8,8'inin fizik tedavi ve rehabilitasyon uygulamalarında gerekli olan sağlık raporu için olduğu tespit edilmiştir.

Kas iskelet sistemi ağrısıyla başvuran hastaların \%57,3'ü

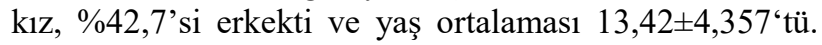
Yaş ortalaması daha önce yapılmış çalışmalara benzer şekilde tespit edilmiştir. Bu durum yaşı daha büyük olan çocukların ağrıyı daha iyi ifade edebilmesine, aile bireylerinde gözlemlenen ağrı modelinin örnek alınmasına, sportif aktivitelere katılımlarının fazla olmasına, enflamatuvar artritlerin, mekanik nedenli bel ve sırt ağrısı sıklığının ergenlik döneminde artmasına bağlı olabilir (4,10,12). Çalışmamızda ağrı şikayeti ile başvuran kız çocuklarının sayısı erkek çocuklardan daha fazla tespit edilmiştir. Groenewald ve ark. kas iskelet sisteminde ağrı şikayetini araştırdıkları çalışmalarında kız çocukların daha fazla ağrı şikayeti ile başvurduğunu saptamıştır (6). Polikliniğe başvuran çocuk hastalarımızda en sık ağrı etiyolojisinin enflamatuvar 
artrit olması ve kız çocukların bu durumdan daha fazla etkilenmesi buna neden olabilir.

Literatürde kas iskelet sistemi ağrı etiyolojisinin en sık travma ve mekanik aşırı kullanım olduğu, ağrı etiyolojilerinin yaş gruplarına göre farklılık gösterebileceği; büyüme kaynaklı ağrının daha küçük yaşlarda ve enflamatuvar artritlerin ise ergenlik döneminde artış gösterdiği bildirilmiştir $(3,4,10)$. Çalışmamızda kas iskelet sistemi ağrısının nedenleri olarak enflamatuvar artritler (\%42,3), spesifik olmayan ağrı $(\% 23,5)$, travma $(\% 13,7)$, skolyoz $(\% 11,5)$, lomber intervertebral disk hastalığı (\%6) ve büyüme kaynaklı ağrı (\%3) tespit edilmiştir. Cavkaytar ve arkadaşları üniversite hastanesine başvuruları inceledikleri çalışmalarında enflamatuvar romatizmal hastalıkların görülme sıklığının ergenlikle beraber arttığını, kas iskelet sistemi ağrı etiyolojisinin en sık nedenlerinin mekanik sebepler ve enflamatuvar romatimal hastalıklar olduğunu bildirmiştir (13). Literatür sonuçlarına benzer şekilde üniversite hastanesine başvurusu olan çocuk hastaları incelediğimiz çalışmamızda en sık ağrı sebebinin enflamatuvar romatizmal hastalıklar olarak tespit edilmesini Düzce ilinde başka romatoloji kliniği ve 3 . basamak hastane olmamasından kaynakladığını düşünmekteyiz.

Çalışmamızda ağrı şikayetinin dağılımı el bileği-el eklemlerinde ağrı \%23,9; bel ve sırt ağrıs1 \%22,6; yumuşak doku kaynaklı ağrı \%14,5; diz ağrısı \%10,7; kalça-pelvis ağrısı \%9,8; ayak bileği-ayak eklemlerinde ağr1 \%7,7; boyun ağrısı \%6; omuz ağrıs1 \%3 ve dirsek ağrısı \%1,7 şeklinde saptanmıştır. Ağrının en sık etiyolojik nedeninin enflamatuvar artrit olmasina paralel şekilde en çok ağrı şikayeti el bileği-el eklemlerinde tespit edilmiştir. Literatürde kas iskelet sistemi ağrı şikayetlerinin yaş grubuna göre değişebildiği bildirilmiştir. 3-14 yaş aralığında olan ve pediatrik acil servise kas iskelet sistemi ağrısı ile başvuran hastaların incelendiği bir çalışmada en sık el bileği, ayak bileği ve parmaklarda ağrı; başka bir çalışmada ise en sık diz, ayak bileği, el bileği ve dirsek olarak saptanmıştır $(3,14)$. Hastalarımızın \%51,3'ünde akut, \%48,7'sinde kronik kas-iskelet sistemi ağrısı tespit edilmiştir. Literatürde kronik ağrının ergenlik döneminde daha sık olduğu ve ağrının kronik hale gelmesi ile çocuğun fiziksel, sosyal, psikolojik ve akademik gelişiminin olumsuz etkilendiği bulunmuştur $(5,12,15)$. Bu nedenle ağrı etiyolojisinin akut dönemde tespiti ve erken tedavi planı ile ağrının kronik hale gelmesini engellemek önem taşır. Ergenlik döneminde artma eğiliminde olan enflamatuvar romatizmal hastalıkların erken tanısı ve etkin tedavisi ile remisyonun sağlanması, eklemlerde kalıcı hasarın engellenmesi önemlidir (15). Kas iskelet sistemi ağr1 şikayetlerine hızlı ve doğru tanı için dikkatli bir öykü almak, ağrının günlük aktivitelere ve okul başarısına olan etkisini sorgulamak, ayrintılı fizik muayene yapmak, ağrının organik nedenlerini analiz ederek altta yatan olası nedenleri tespit edip ağrı kronikleşmeden etkin tedavi planını yapmak hedeflenmelidir. Birinci basamak sağlık kuruluşlarında çalışan hekimlerin çocukluk çağı kas iskelet sistemi ağrılarına yaklaşım açısından farkındalıklarını arttırmanın, okul taramalarına kas iskelet sistemi ağrı sorgulamasını da dahil etmenin erken tanıda, etkin sevk sisteminde ve üçüncü basamak hastanelerde olan yığılmaları engelleme hususunda faydalı olabileceğini düşünmekteyiz.

Çalışmamızda çocukluk çağı kas iskelet sistemi ağrı şikayetinin en sik nedeni enflamatuvar artritler olarak tespit edildi. Çocuk hastaların daha çok fizyoterapi alabilmek, sosyal ve eğitsel haklardan yararlanmak amacıyla polikliniğe başvurduğu saptandı. Tek merkezli ve retrospektif olması çalışmanın kısıtlılıkları olarak sayılabilir. Bu nedenle ülkemizde çocuklarda kas-iskelet sistemi ağrısı ve engellilik ile ilgili çok merkezli ve prospektif çalışmaların yapılmasına ihtiyaç vardır.

Yazarların Katkıları: Fikir/Kavram: T.E.S.; Tasarım: T.E.S.; Veri Toplama ve/veya İşleme: T.E.S., B.A., M.NÇ.; Analiz ve/veya Yorum: S.A.; Literatür Taraması: T.E.S., B.A., M.NÇ.; Makale Yazımı: T.E.S., B.A., M.NÇ.

\section{KAYNAKLAR}

1. Perquin CW, Hazebroek-Kampschreur AA, Hunfeld JA, Bohnen AM, van Suijlekom-Smit LW, Passchier $\mathrm{J}$, et al. Pain in children and adolescents: a common experience. Pain. 2000; 87(1): 51-8.

2. King S, Chambers CT, Huguet A, Mac Nevin RC, Mc Grath PJ, Parker L, et al. The epidemiology of chronic pain in children and adolescents revisited: a systematic review. Pain. 2011; 152(12): 2729-38.

3. Inocencio J, Carro MA, Flores M, Carpio C, Mesa S, Marín M. Epidemiology of musculoskeletal pain in a pediatric emergency department. Rheumatol Int. 2016; 36(1): 83-9.

4. Feinstein AB, Sturgeon JA, Bhandari RP, Yoon IA, Ross AC, Huestis SA, et al. Risk and resilience in pediatric pain: The roles of parent and adolescent catastrophizing and acceptance. Clin J Pain. 2018; 34(12): 1096-105.

5. Friedrichsdorf SJ, Giordano J, Dakoji KD, Warmuth A, Daughtry C, Schulz AC. Chronic pain in children and adolescent: diagnosis and treatment of primary pain disorders in head, abdomen, muscles and joints. Children. 2016; 3(4): 42.

6. Groenewald CB, Essner BS, Wright D, Fesinmeyer DM, Palermo TM. The economic costs of chronic pain among a cohort of treatment seeking adolescents in the United States. The J Pain. 2014; 15(9): 925-33.

7. who.int [Internet]. Geneva: World Bank. World Report on Disability; 2011 [Cited: 2020 October 17]. Available from: https://www.who.int/disabilities/world_report/2011/re port.pdf

8. Terzi R, Altın F. Özürlü sağlık kurulunda değerlendirilen hastaların lokomotor sistem özürlülüklerinin incelenmesi. Türk Osteoporoz Dergisi. 2014; 20(2): 60-4.

9. resmigazete.gov.tr [Internet]. T.C. Resmi Gazete. Erişkinler İçin Engellilik Değerlendirmesi Hakkında Yönetmelik. Resmi gazete tarih: 20 Şubat 2019. Resmi gazete sayı: 30692. [Erişim tarihi: 17 Kasım 2020]. Erişim adresi: https://www.resmigazete.gov.tr/eskiler/2019/02/2019 0220-2.htm.

10. De Inocencio J. Epidemiology of musculoskeletal pain in primary care. Arch Dis Child. 2004; 89(5): 
431-4.

11. Merskey H, Bogduk N. International Association for the Study of Pain. Classification of chronic pain: Descriptions of chronic pain syndromes and definitions of pain terms. 2th ed. Seattle: IASP Press; 2002.

12. King S, Chambers CT, Huguet A, MacNevin RC, McGrath PJ, Parker L, et al. The epidemiology of chronic pain in children and adolescents revisited: A systematic review. Pain. 2011; 152(12): 2729-38.

13. Cavkaytar Ö, Düzova A, Tekşam Ö, Karabulut E, Derman O, Kale G, et al. Final diagnosis of children and adolescents with musculoskeletal complaints. Minerva Pediatrica. 2017; 69(1): 50-8.

14. De Inocencio J. Musculoskeletal pain in primary pediatric care: analysis of 1000 consecutive general pediatric clinic visits. Pediatrics. 1998; 102(6): 63.

15. Sandborg C. Expression of autoimmunity in the transition from childhood to adulthood: Role of cytokines and gender. J Adolesc Health. 2002; 30(4): 76-80. 